\title{
The effect of therapeutic pleural drainage on the short- and long- term sequelae of tuberculous pleural effusions
}

\author{
E Wilken, MB ChB, FCP; H Fengels, MD; F Swart, ND Clin Tech; D Maree, ND Clin Tech; J W Bruwer, MB ChB, FCP, Cert Pulm; \\ E M Batubara, MD, FCCP, SBIM, SF-AP; E M Irusen, MB ChB, FCP, PhD; C F N Koegelenberg, MB ChB, FCP, FRCP, PhD
}

Division of Pulmonology, Department of Medicine, Faculty of Medicine and Health Sciences, Stellenbosch University and Tygerberg Hospital, Cape Town, South Africa

Corresponding author: E Wilken (elismawilken@gmail.com)

Background. Tuberculosis (TB) remains a common cause of pleural exudates in many parts of the globe. Pleural fibrosis with restriction is a well-known complication of tuberculous pleuritis. Current evidence suggests that pleural drainage offers little benefit over and above anti-TB treatment in improving pulmonary function.

Methods. We enrolled 20 patients with proven tuberculous pleural effusions (mean age 32.7 years, 10 males, $12 \mathrm{HIV}$-positive), and performed therapeutic pleural drainage in 10 randomly selected cases. Pulmonary function testing (PFT), chest radiography and transthoracic ultrasound were performed on all patients before treatment and at $7-10$ days, 3 months and 6 months.

Results. Complete therapeutic drainage was achieved in only 4 of the 10 patients randomised to undergo drainage. No significant immediate benefit was achieved in the 10 patients assigned to intervention. However, compared with the non-intervention group, the intervention group showed significant changes in several functional parameters at 6 months, including changes in forced vital capacity from baseline $(1.40 \mathrm{~L}$ v. $0.65 \mathrm{~L} ; p<0.001)$, forced expiratory volume in 1 second $(1.37 \mathrm{~L} \mathrm{v.} 0.60 \mathrm{~L} ; p=0.002)$, total lung capacity $(1.76 \mathrm{~L} \mathrm{v.} 0.88 \mathrm{~L} ; p=0.034)$ and diffusion capacity for carbon monoxide $(7.42 \mathrm{v} .2 .19 \mathrm{~mL} / \mathrm{min} / \mathrm{mmHg}, p=0.013)$. No difference was observed in the change in 6 -minute walking distance ( $113.4 \mathrm{~m} \mathrm{v} .126 \mathrm{~m} ; p=0.798$ ) compared with the control group at 6 months.

Conclusions. Therapeutic drainage may offer additional medium- and long-term functional benefits to patients with pleural TB, in addition to anti-TB drug therapy alone, as evident in the improvement in PFT results.

S Afr Respir J 2016;22(3):60-66. DOI:10.7196/SARJ.2016.v22i3.79

Tuberculosis (TB) is the most frequent cause of death due to infectious disease worldwide. ${ }^{[1,2]} \mathrm{TB}$ pleural involvement is the second most common extrapulmonary manifestation of TB after TB lymphadenitis. It is well documented in both primary and postprimary TB. ${ }^{[3]}$ Involvement ranges from tuberculous pleurisy to exudative and caseous pleurisy to frank empyema. ${ }^{[4]}$ In the developed world, tuberculous pleural involvement remains rare with $\mathrm{TB}$ accounting for $<1 \%$ of exudates. However, in the developing world, especially in the setting of HIV co-infection, TB may be associated with up to $80 \%$ of pleural effusions. ${ }^{[4]}$

Thoracocentesis is the initial mandatory diagnostic procedure, and typically reveals a lymphocytic exudate, rich in protein, glucose deplete and with elevated lactate dehydrogenase (LDH) and adenosine deaminase (ADA) levels. The diagnostic yield of thoracocentesis is $\sim 93 \%$, which could be improved to $100 \%$ with the addition of a thoracoscopic pleural biopsy. ${ }^{[5]}$

Pleural fibrosis or fibrothorax is a well-described complication of tuberculous pleurisy ${ }^{[4,6]}$ Uncertainty remains regarding the prevalence of fibrothorax and permanent pleural thickening, with some sources suggesting a prevalence of $50 \%$, while others suggest that it is as low as $5 \% .{ }^{[4,7]}$ This variation could be explained by differences in demographics and background TB prevalence. Many experienced thoracoscopists believe that complete drainage of the pleural effusion results in a reduction in the development of pleural fibrosis, ${ }^{[4,8]}$ but empirical data showing a potential benefit of effective drainage of pleural effusion in the prevention of pleural fibrosis are lacking.

In 2003, Lai et al. ${ }^{[9]}$ could not demonstrate a benefit of pleural drainage in the prevention of pleural fibrosis in a randomised trial, but the effectiveness of pleural drainage was not evaluated in that study. In a subsequent study, Chung et al..$^{[10]}$ showed that effective drainage of TB pleural effusion lowered the risk of fibrosis compared with partial drainage. Their data suggested that such drainage might in fact be of benefit in reducing the risk of developing residual pleural fibrosis. Owing to a lack of consensus, the current standard of care for TB pleural effusion does not include pleural drainage and only consists of anti-TB drugs.

Factors that significantly increase the probability of development of pleural fibrosis include the severity of the initial change in pleural glucose, $\mathrm{pH}$ and tumour necrosis factor-alpha levels. ${ }^{[7]}$ It has also been suggested that the degree of pleural thickening can be estimated by the response to 2 weeks of anti-TB treatment. ${ }^{[1]}$ Additionally, a septated ultrasonographic appearance of the pleural effusion, a positive TB culture on pleural fluid and an elevated LDH level are also associated with an increased risk of developing pleural fibrosis. ${ }^{[12]}$

Pulmonary function tests (PFTs) are an objective measure to monitor the response and effectiveness of treatment of TB pleural effusion. The 6-minute walking distance (6MWD) is used to determine objective functional exercise capacity.

A spectrum of sequelae is observed in patients with pleural fibrosis, ranging from asymptomatic radiographic abnormalities to severe restrictive ventilatory impairment. ${ }^{[9,10,12,13]}$

\section{Objective}

To investigate the additional benefits of once-off pleural drainage in addition to medical management in the prevention of short- and long-term sequelae of tuberculous pleural effusions. The effectiveness of the intervention was measured by looking at changes in PFT results over time. 


\section{Methods}

Study design and population

This randomised controlled interventional study was carried out from October 2012 to September 2013 in the Division of Pulmonology at Tygerberg Academic Hospital, a 1200 -bed hospital in Cape Town, South Africa (SA). It is one of two referral centres and renders a tertiary service to a population of approximately 1.5 million people. The incidence of pulmonary TB in the Western Cape Province is 933 cases per 100000 population, the highest recorded incidence after China and India according to the World Health Organization. ${ }^{[14]}$

Ethical approval for the study was obtained from the Stellenbosch University Human Research Ethics Committee (Ethics ref.: N12/07/040). Every patient gave informed consent to enrol in this study in writing.

Patients aged $>18$ years with a high clinical suspicion of TB and radiological evidence of a pleural effusion were enrolled. A high clinical suspicion included patients known to have HIV infection and those with a persistent cough lasting $>3$ weeks, haemoptysis, weight loss of $>4 \mathrm{~kg}$, intermittent fever for $>3$ weeks and drenching night sweats for $>2$ weeks. Patients were included if they could give written consent and had a chest radiograph (CXR) showing $>30 \%$ involvement of the hemithorax and at least two clinical indicators to suggest TB. Any patient found not to have TB was excluded from the study. Other exclusion criteria were a recent history of invasive procedures in the pleural cavity or recent penetrating chest wall trauma.

\section{Initial evaluation and management}

A baseline CXR with posteroanterior and lateral films along with spirometric assessment according to the guidelines of the American Thoracic Society (ATS) was performed on all patients. ${ }^{[15-18]}$ Initial CXR effusion size was graded as moderate ( $<50 \%$ of a hemithorax), moderate to large (50 - 75\% of a hemithorax) or large ( $>75 \%$ of a hemithorax). Spirometrics (MasterScreen Jaeger, Germany, version 02.00, 2011) included a flow-volume loop, diffusion capacity for carbon monoxide $\left(\mathrm{DL}_{\mathrm{CO}}\right)$ and plethysmography. To evaluate patients' functional exercise capacity, we performed a 6MWD according to the ATS criteria ${ }^{[19]}$ and graded symptoms according to Borg, ${ }^{[20]}$ including dyspnoea and exhaustion with a visual analogue scale.

Participants were randomly allocated at a 1:1 ratio to either a control group or an intervention group at the onset of presentation. Diagnostic thoracocentesis (at least $50 \mathrm{ml}$ of pleural fluid) and pleural biopsy (more than four samples) with an Abrams needle were performed in a sitting position and under ultrasound guidance according to standardised guidelines. ${ }^{[21-23]}$ The intervention group received therapeutic once-off pleural fluid drainage with an Arrow percutaneous cavity drainage catheterisation set (Teleflex, SA). Thoracocentesis was suspended if spontaneous cessation of fluid drainage occurred or if the patient experienced discomfort with exacerbation of symptoms or vagal manifestations. The patient was observed and oxygen therapy given if saturation was $<90 \%$. After complete drainage, the efficacy was assessed by an ultrasound scan $(<0.5 \mathrm{~cm}$ of pleural fluid visible in the posterior-lateral recess) and chest radiography $(<0.5 \mathrm{~cm}$ of blunting of the costophrenic angle). The measurements were defined as partial drainage $(0.5-1.0 \mathrm{~cm})$ or completely drained $(<0.5 \mathrm{~cm})$. Spirometric assessment (flow-volume and plethysmography) and 6MWD were repeated in all patients. Both groups were treated with standard anti-TB therapy. ${ }^{[24]}$

Pleural fluid was analysed by means of routine biochemistry, including ADA, cytology and cell count. Liquid TB cultures of pleural fluid and tissue biopsy were performed with a BACTEC MGIT 960 System (Becton, Dickinson \& Co, USA). TB was confirmed by the appearance of granulomas in the biopsy and a positive fluid or biopsy TB culture. Positive TB cultures were tested for drug resistance (GenoType MTBDRplus, Hain Life Science GmbH, Germany). ${ }^{[5]}$ Surgical interventions (including decortication) were considered in patients with pleural empyema or persistent severe restriction (forced vital capacity (FVC) $<50 \%$ ) after completed medical treatment. ${ }^{[1]}$ Patients who were found not to have TB were treated according to protocol for the diagnosis made and excluded from the study.

\section{Follow-up}

All participants were followed up after 1 week. The laboratory results were reviewed, anti-TB treatment, where relevant, was continued for at least 6 months and further special investigations, where appropriate, were organised. This was all done according to the standard operating procedure at Tygerberg Academic Hospital. All patients with confirmed pleural TB were subsequently followed up at 3 and 6 months. The CXR (Fig. 1), spirometric assessments and a $6 \mathrm{MWD}$ were performed at each visit. The greatest linear width of pleural opacity on the erect PA CXR was classified as follows: $<2 \mathrm{~mm}$ : radiologically normal; 2 $4.9 \mathrm{~mm}$ : radiologically abnormal; $5-10 \mathrm{~mm}$ : pleural thickening; and $>10 \mathrm{~mm}$ : fibrothorax.

Estimated overall pleural thickening was classified as involvement of less than onethird of the hemithorax, one-third to twothirds of the hemithorax, or more than twothirds of the hemithorax.

\section{Statistical analysis}

The changes in FVC after 1 week and 3 and 6 months were compared with the baseline value. An unpaired $t$-test at an alpha level of $5 \%$ was used to compare the mean change in FVC between the intervention and control groups. Further key secondary endpoints were analysed in line with the primary

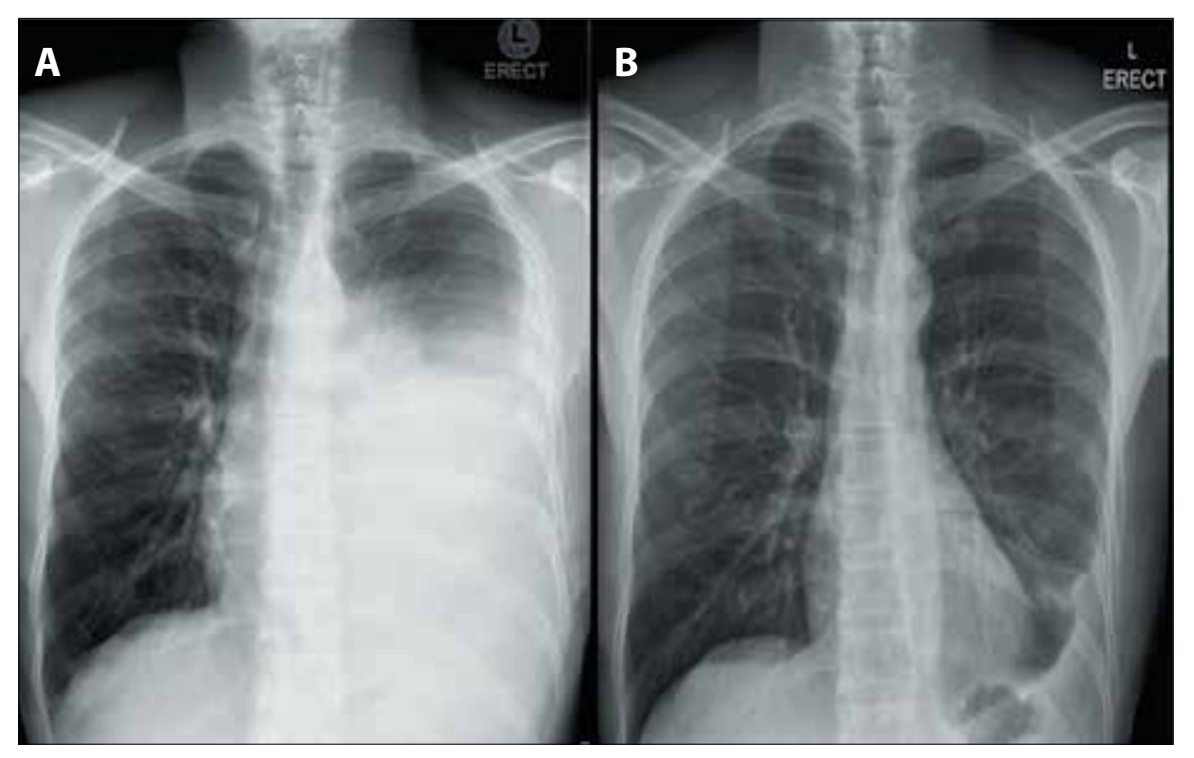

Fig. 1. Radiographs at baseline (A) and after 6 months of treatment (B), demonstrating pleural thickness. 
endpoints (changes in forced expiratory volume in 1 second $\left(\mathrm{FEV}_{1}\right)$, total lung capacity (TLC), $\mathrm{DL}_{\mathrm{CO}}$ and $6 \mathrm{MWD}$ after 1 week and 3 and 6 months). Missing values for assessment of change were replaced with zero, following a conservative strategy. Baseline characteristics were analysed using means and standard deviations (SDs) for continuous and absolute frequencies for categorical variables. A $p$-value of $<0.05$ was considered significant.

\section{Outcome}

For a short-term sequelae primary outcome parameter we defined change in FVC in litres after 1 week, for medium term after 3 months and for long term after 6 months. Key secondary outcome parameters included changes in $\mathrm{FEV}_{1}$, TLC, $\mathrm{DL}_{\mathrm{CO}}$ and 6MWD and the prevalence of fibrothorax after 6 months of treatment. The need for surgery was taken as the main clinical long-term sequelae parameter.

\section{Results}

Baseline observations and interventions

Thirty-seven patients were referred for the study, of whom 13 were excluded ( 3 had empyemas, 3 had pneumonia, 3 had negative results on testing for TB, 1 was $<18$ years of age and 3 had other reasons). All patients were randomised from the start, and either a diagnostic tap or therapeutic drainage was performed. Eleven patients were randomised to therapeutic pleural drainage, but 1 was lost to followup after the initial visit, leaving 10 patients with completed data in each study arm.

The mean age of the 20 patients was 32.7 years (SD 8.7); 12 were HIV-positive. The general characteristics of the group are summarised in Table 1 and the results of diagnostic thoracocentesis in Table 2. The mean volume drained during therapeutic drainage was $1139 \mathrm{~mL}$ (SD 711, range 250 - 2 700). Aspiration was abandoned in 6 patients owing to suspected re-expansion pulmonary oedema and/or discomfort.

\section{Primary and key secondary outcomes}

Lung function parameters measured at baseline, 1 week, 3 months and 6 months are summarised in Tables 3 - 5 .

With regard to the primary outcome variable, patients randomised to therapeutic drainage experienced a significantly greater improvement in FVC than the control group at 3 months (mean difference $1.40 \mathrm{~L}$ (SD 0.44) in the intervention group v. 0.34 L (SD 0.46) in the control group; $p<0.001$ ) and at 6 months (1.40 L (SD 0.44) v. $0.65 \mathrm{~L}$ (SD 0.39); $p<0.001$ ) (Fig. 2A). The mean percentage predicted change in FVC from baseline in the intervention group was significantly higher than in the control group at 3 months (36.3\% (SD 9.4) v. 9.0\% (SD 12.7); $p<0.001$ ) and 6 months (43.93\% (SD 8.83) v. 16.38\% (SD 11.38); $p<0.001$ ).

$\mathrm{FEV}_{1}$ in the intervention group improved significantly, with a mean change from baseline at 3 months of $1.08 \mathrm{~L}$ (SD 0.41) v. $0.38 \mathrm{~L}$ (SD 0.42); $p=0.001$ in the control group and $1.37 \mathrm{~L}(\mathrm{SD} 0.56)$ v. $0.60 \mathrm{~L}$ (SD 0.34); $p=0.002$ at 6 months (Fig. 2B).

Patients randomised to therapeutic drainage also experienced significantly greater improvement in TLC, with a change of $1.45 \mathrm{~L}$ (SD 0.56) v. $0.56 \mathrm{~L}$ (SD 0.78); $p=0.009$ at 3 months, and $1.76 \mathrm{~L}$ (SD $0.94)$ v. $0.88 \mathrm{~L}$ (SD 0.76); $p=0.034$ at 6 months (Fig. $2 \mathrm{C}$ ).

Changes in $\mathrm{DL}_{\mathrm{co}}$ after 3 months (mean change $6.43 \mathrm{~mL} / \mathrm{min} / \mathrm{mmHg}$ (SD 3.77) in the intervention group v. $0.57 \mathrm{~mL} / \mathrm{min} / \mathrm{mmHg}$ (SD 4.18) in the control group; $p=0.005)$ and 6 months $(7.42 \mathrm{~mL} / \mathrm{min} / \mathrm{mmHg}$ (SD 4.63) in the intervention group v. $2.19 \mathrm{~mL} / \mathrm{min} / \mathrm{mmHg}$ (SD 3.84) in the control group; $p=0.013$ ) were also statistically significant (Fig. 2D).

6MWD improved in both groups, being $113.5 \mathrm{~m}$ (SD 64.6) in the intervention group v. $85.9 \mathrm{~m}$ (SD 69.4) in the control group $(p=0.369)$ at 3 months and $113.4 \mathrm{~m}$ (SD 131.02) in the intervention group v. $126 \mathrm{~m}$ (SD 78.8) in the control group ( $p=0.798)$ at 6 months. Improvement in the intervention group was not significantly superior to that in the control group (Fig. 2E).

As no patient showed severe restriction $(\mathrm{FVC}<50 \%)$ after 3 or 6 months, surgery was not considered in any patient.

\section{Complications}

Initial pleural aspiration and biopsy were uncomplicated in all study patients. Re-expansion pulmonary oedema and/or patient discomfort resulted in the premature termination of 6 of the 10 attempts at complete pleural drainage. The procedure was stopped as soon as the patient experienced symptoms of distress or discomfort, and the patient was observed and given supplemental oxygen if the saturation was $<90 \%$. Patients recovered quickly, and no patient needed admission. The procedure was also abandoned if the drainage of fluid

Table 1. Clinical and radiological characteristics of the study population $(N=20)$

\begin{tabular}{lll}
\hline Parameter & $\begin{array}{l}\text { Study group } \\
(\boldsymbol{n}=\mathbf{1 0})\end{array}$ & $\begin{array}{l}\text { Control group } \\
(\boldsymbol{n}=\mathbf{1 0})\end{array}$ \\
\hline Age (years), mean (SD) & $27.9(6.8)$ & $37.5(10.63)$ \\
Weight (kg), mean (SD) & $61.6(14.1)$ & $56.7(10.14)$ \\
Height (cm), mean (SD) & $164.0(7.0)$ & $164.45(11.8)$ \\
Males/females, $n$ & $3 / 7$ & $7 / 3$ \\
HIV-positive, $n$ & 4 & 8 \\
Loculations, $n$ & 3 & 4 \\
Effusion side, $n$ & & \\
$\quad$ Left & 4 & 5 \\
$\quad$ Right & 6 & 5 \\
Effusion size, $n$ & & \\
$\quad<50 \%$ & 0 & 2 \\
$50-75 \%$ & 7 & 8 \\
$>75 \%$ & 3 &
\end{tabular}

Table 2. Pleural fluid and blood results in the study population $(N=20)$

Pleural fluid

ADA (U/L)

72.56

$\mathrm{LDH}(\mathrm{U} / \mathrm{L})$

749.1

Total protein $(\mathrm{g} / \mathrm{L})$

63.6

Glucose ( $\mathrm{mmol} / \mathrm{L})$

4.1

$\mathrm{pH}$

7.3

Lymphocytes (\%)

81.55

Neutrophils (\%)

13.0

Blood

LDH (U/L)

293.11

Total protein $(\mathrm{g} / \mathrm{L})$

80.8

Glucose (mmol/L) 
Table 3. Lung function parameters (mean (SD)) of all study patients at baseline and immediately after drainage

\begin{tabular}{|c|c|c|c|c|c|c|}
\hline \multirow[b]{2}{*}{ Parameter } & \multirow[b]{2}{*}{ Variable } & \multicolumn{3}{|c|}{ Initial assessment } & \multicolumn{2}{|c|}{ Post drainage } \\
\hline & & $\begin{array}{l}\text { Not drained } \\
(n=10)\end{array}$ & $\begin{array}{l}\text { Therapeutic drainage } \\
(n=10)\end{array}$ & $p$-value & $\begin{array}{l}\text { Therapeutic drainage } \\
(n=10)\end{array}$ & $p$-value \\
\hline \multirow[t]{2}{*}{ FVC } & Absolute (L) & $2.13(0.61)$ & $1.66(0.48)$ & 0.074 & $1.65(0.43)$ & 0.938 \\
\hline & $\%$ predicted & $55.67(9.11)$ & $43.0(9.1)$ & 0.006 & $43.6(10.8)$ & 0.887 \\
\hline \multirow[t]{2}{*}{$\mathrm{FEV}_{1}$} & Absolute (L) & $1.74(4.49)$ & $1.45(0.41)$ & 0.173 & $1.43(0.35)$ & 0.790 \\
\hline & $\%$ predicted & $53.71(7.73)$ & $43.9(10.0)$ & 0.024 & $43.6(11.6)$ & 0.932 \\
\hline \multirow[t]{2}{*}{ TLC } & Absolute (L) & $4.01(0.87)$ & $3.00(0.70)$ & 0.010 & $3.40(0.79)$ & 0.047 \\
\hline & $\%$ predicted & $73.32(20.12)$ & $56.6(13.8)$ & 0.044 & $63.9(13.7)$ & 0.068 \\
\hline \multirow[t]{2}{*}{$\mathrm{DL}_{\mathrm{CO}}$} & $\begin{array}{l}\text { Absolute }(\mathrm{mL} / \mathrm{min} / \\
\mathrm{mmHg})\end{array}$ & $15.67(4.44)$ & $14.32(3.49)$ & 0.463 & N/A & N/A \\
\hline & $\%$ predicted & $55.19(9.92)$ & $50.2(11.2)$ & 0.303 & N/A & $\mathrm{N} / \mathrm{A}$ \\
\hline 6MWD & Absolute (m) & $465.4(100.54)$ & $452.6(110.5)$ & 0.790 & $476.5(102.7)$ & 0.070 \\
\hline
\end{tabular}

Table 4. Lung function parameters (mean (SD)) of all study patients after 1 week

\begin{tabular}{|c|c|c|c|c|}
\hline \multirow[b]{2}{*}{ Parameter } & \multirow[b]{2}{*}{ Variable } & \multicolumn{2}{|c|}{ Follow-up, 1 week } & \multirow[b]{2}{*}{$p$-value } \\
\hline & & $\begin{array}{l}\text { Not drained } \\
(n=10)\end{array}$ & $\begin{array}{l}\text { Therapeutic } \\
\text { drainage } \\
(n=10)\end{array}$ & \\
\hline \multirow[t]{4}{*}{ FVC } & Absolute (L) & $2.36(0.62)$ & $2.27(0.60)$ & 0.749 \\
\hline & $\%$ predicted & $61.9(8.3)$ & $58.9(11.1)$ & 0.496 \\
\hline & Change from baseline (L) & $0.23(0.33)$ & $0.61(0.48)$ & 0.054 \\
\hline & $\%$ change & $6.2(8.6)$ & $15.8(12.4)$ & 0.060 \\
\hline \multirow[t]{4}{*}{$\mathrm{FEV}_{1}$} & Absolute (L) & $1.87(0.53)$ & $1.95(0.62)$ & 0.768 \\
\hline & $\%$ predicted & $58.1(10.5)$ & $58.6(13.4)$ & 0.929 \\
\hline & Change from baseline (L) & $0.13(0.26)$ & $0.50(0.43)$ & 0.034 \\
\hline & $\%$ change & $4.4(8.3)$ & $14.8(12.6)$ & 0.044 \\
\hline \multirow[t]{4}{*}{ TLC (L) } & Absolute (L) & $4.21(0.74)$ & $3.60(0.70)$ & 0.075 \\
\hline & $\%$ predicted & $76.4(11.3)$ & $67.6(9.5)$ & 0.077 \\
\hline & Change from baseline (L) & $0.21(0.66)$ & $0.60(0.59)$ & 0.173 \\
\hline & $\%$ change & $3.1(14.0)$ & $11.0(10.8)$ & 0.173 \\
\hline \multirow[t]{4}{*}{$\mathrm{DL}_{\mathrm{CO}}$} & Absolute (mL/min/mmHg) & $15.70(4.33)$ & $16.22(3.79)$ & 0.768 \\
\hline & $\%$ predicted & $55.4(10.3)$ & $56.5(10.6)$ & 0.818 \\
\hline & $\begin{array}{l}\text { Change from baseline }(\mathrm{mL} / \mathrm{min} / \\
\mathrm{mmHg})\end{array}$ & $0.00(1.60)$ & $1.89(2.03)$ & 0.032 \\
\hline & $\%$ change & $0.25(5.4)$ & $6.4(0.6)$ & 0.047 \\
\hline \multirow[t]{2}{*}{$6 \mathrm{MWT}$} & Absolute (m) & $501.1(87.3)$ & $485.6(89.2)$ & 0.701 \\
\hline & Change from baseline (m) & $35.7(50.7)$ & $33.0(60.9)$ & 0.914 \\
\hline
\end{tabular}

spontaneously ceased. No pneumothorax or major haemorrhage resulted.

\section{Discussion}

We found that at 3 and 6 months' follow-up, patients with confirmed tuberculous pleural effusions randomised to therapeutic pleural drainage showed significantly superior improvement in several lung function parameters to those who did not receive
TB therapy and early complete drainage are adequate for the treatment of TB pleurisy. Their study did not include a control group. A subsequent randomised controlled trial by Lai et al. ${ }^{[9]}$ found that the addition of pleural drainage to anti-TB medical treatment did not have a beneficial effect on restrictive pulmonary thickness (RPT) development or shorten the duration of fever or other clinical symptoms. Lai et al. ${ }^{[9]}$ failed to show a significant improvement in FVC (treatment group $85.5 \%$ v. control group $88 \%$; $p=0.568)$, TLC and $\mathrm{FEV}_{1}$ were not measured, and effectiveness of drainage was not evaluated. Dyspnoea was the only proven benefit, and showed faster improvement in the drained group (median 4 days v. 8 days; $p<0.001$ ).

In contrast, a recent study by Bhuniya et al. ${ }^{[26]}$ showed significant differences in mean percentage predicted $\mathrm{FEV}_{1}$ (drained group $87.62 \%$ v. control group $84.92 \% ; p=0.02$ ) and FVC (84.46 L v. $83.31 \mathrm{~L} ; p=0.001)$ after 6 months, drainage being performed using pleural manometry. They reported a lower appearance of RPT in patients who underwent drainage and commented that patients with therapeutic thoracocentesis experienced immediate relief from dyspnoea after drainage, although this finding was not substantiated with any objective measure.

Previous studies have reported immediate improvement in FVC and $\mathrm{FEV}_{1}$, with both showing an increase in excess of $10 \%$ after thoracocentesis of large pleural effusions. ${ }^{[27-29]}$ We did not find any immediate improvement in FVC or $\mathrm{FEV}_{1}$ after the procedure, but this may be due to pain and coughing caused by the drainage process. TLC showed a significant immediate improvement $(3.00 \mathrm{~L}$ before drainage v. $3.40 \mathrm{~L}$ after drainage; $p=0.047$ ). 
Table 5. Lung function parameters (mean (SD)) of all study patients after 3 and 6 months

\begin{tabular}{|c|c|c|c|c|c|c|c|}
\hline \multirow[b]{2}{*}{ Parameter } & \multirow[b]{2}{*}{ Variable } & \multicolumn{3}{|c|}{ Follow-up, 3 months } & \multicolumn{3}{|c|}{ Follow-up, 6 months } \\
\hline & & $\begin{array}{l}\text { Not drained } \\
(n=10)\end{array}$ & $\begin{array}{l}\text { Therapeutic } \\
\text { drainage } \\
(n=10)\end{array}$ & $p$-value & $\begin{array}{l}\text { Not drained } \\
(n=10)\end{array}$ & $\begin{array}{l}\text { Therapeutic } \\
\text { drainage } \\
(n=10)\end{array}$ & $p$-value \\
\hline \multirow[t]{4}{*}{ FVC } & Absolute (L) & $2.46(0.59)$ & $3.06(0.72)$ & 0.059 & $2.78(0.61)$ & $3.38(0.93)$ & 0.108 \\
\hline & $\%$ predicted & $64.7(9.6)$ & $79.3(11.2)$ & 0.006 & $72.05(8.85)$ & $86.95(11.01)$ & 0.004 \\
\hline & Change from baseline (L) & $0.34(0.46)$ & $1.40(0.44)$ & 0.001 & $0.65(0.39)$ & $1.40(0.44)$ & $<0.001$ \\
\hline & $\%$ change & $9.0(12.7)$ & $36.3(9.4)$ & $<0.001$ & $16.38(11.38)$ & $43.93(8.83)$ & $<0.001$ \\
\hline \multirow[t]{4}{*}{$\mathrm{FEV}_{1}$} & Absolute (L) & $2.12(0.62)$ & $2.53(0.61)$ & 0.154 & $2.34(0.65)$ & $2.82(0.81)$ & 0.159 \\
\hline & $\%$ predicted & $67.5(14.7)$ & $76.4(12.6)$ & 0.163 & $71.02(13.54)$ & $84.37(12.86)$ & 0.036 \\
\hline & Change from baseline (L) & $0.38(0.42)$ & $1.08(0.41)$ & 0.001 & $0.60(0.34)$ & $1.37(0.56)$ & 0.002 \\
\hline & $\%$ change & $13.7(14.3)$ & $32.5(11.2)$ & 0.004 & $17.31(11.27)$ & $40.5(12.17)$ & $<0.001$ \\
\hline \multirow[t]{4}{*}{ TLC } & Absolute (L) & $4.57(0.94)$ & $4.45(0.80)$ & 0.760 & $4.89(0.84)$ & $4.76(1.19)$ & 0.783 \\
\hline & $\%$ predicted & $81.5(15.9)$ & $84.1(9.5)$ & 0.658 & $87.06(11.26)$ & $87.8(9.03)$ & 0.875 \\
\hline & Change from baseline (L) & $0.56(0.78)$ & $1.45(0.56)$ & 0.009 & $0.88(0.76)$ & $1.76(0.94)$ & 0.034 \\
\hline & $\%$ change & $8.2(14.8)$ & $27.5(8.1)$ & 0.002 & $13.74(14.86)$ & $31.19(13.51)$ & 0.013 \\
\hline \multirow[t]{4}{*}{ DLco } & Absolute (mL/min/mmHg) & $16.17(4.52)$ & $20.75(3.78)$ & 0.028 & $17.86(5.02)$ & $21.74(5.3)$ & 0.11 \\
\hline & $\%$ predicted & $58.0(10.8)$ & $72.2(6.8)$ & 0.003 & $62.38(10.76)$ & $75.18(10.8)$ & 0.016 \\
\hline & Change from baseline $(\mathrm{mL} / \mathrm{min} / \mathrm{mmHg})$ & $0.57(4.18)$ & $6.43(3.77)$ & 0.005 & $2.19(3.84)$ & $7.42(4.63)$ & 0.013 \\
\hline & $\%$ change & $2.0(14.0)$ & $22.1(12.1)$ & 0.004 & $7.19(12.25)$ & $25.03(14.11)$ & 0.007 \\
\hline \multirow[t]{2}{*}{ 6MWD } & Absolute (m) & $551.3(93.8)$ & $566.1(81.1)$ & 0.708 & $591.4(92.58)$ & $566(82.79)$ & 0.523 \\
\hline & Change from baseline $(\mathrm{m})$ & $85.9(69.4)$ & $113.5(64.6)$ & 0.369 & $126(78.8)$ & $113.4(131.02)$ & 0.798 \\
\hline
\end{tabular}

We used the 6MWD to objectively evaluate performance-based functional exercise capacity. It is a cheap and easy test to perform, ${ }^{[19]}$ but unfortunately only measures the submaximal level of functional capacity, and the results are influenced by the patient's own motivation and set pace. We did not find any difference in $6 \mathrm{MWD}$ (as measured by Borg ${ }^{[20]}$ ) between the two groups at any time during follow-up. The minimal clinical important difference for the 6MWD is estimated to be between $54 \mathrm{~m}$ and $80 \mathrm{~m},{ }^{[30]}$ which both groups achieved at 3 and 6 months. The lack of statistical significance could be explained by the study being under-powered for the test, or may suggest that a different objective test should have been used. ${ }^{[19]}$ Another consideration is that both groups' performance-based functional exercise capacity improved despite intervention.

On the other hand, most patients experienced clinical improvement of chest pain and relief of dyspnoea after drainage of the effusion. The greatest dyspnoea relief was achieved immediately after drainage, which confirms findings of former studies. ${ }^{[25,26,31]}$

Although our numbers were small, it appears that complete drainage seems to reduce RPT. Earlier studies reported that an RPT of $>10 \mathrm{~mm}$ caused significant clinical symptoms in patients with pleural $\mathrm{TB}$, with incidences ranging from $26 \%$ to $50.4 \% .^{[9,26,32]}$ In our study there were twice as many patients with an RPT of $>10 \mathrm{~mm}(60 \%)$ in the control group than in the intervention group (30\%), which is in accordance with similar current studies. ${ }^{[32]}$

In contrast to previous studies, ${ }^{[10,25]}$ ours was a randomised controlled trial and as such we focused on FVC improvement and investigated the influence of drainage on all lung function parameters, including TLC and $\mathrm{DL}_{\mathrm{CO}}$. Another difference to previous studies ${ }^{[9,10]}$ is that we decided to use a single once-off drainage for achieving dryness of pleural effusion, not pigtail drainage over several days. The value of this is that once-off drainage is an available treatment procedure, simple to perform at primary healthcare level. Moreover, we evaluated effectiveness of drainage after the procedure.

\section{Study limitations}

A limitation of our study is that despite randomisation, the two groups differed with regard to their baseline characteristics. From the outset, the intervention group had larger effusion sizes, higher dyspnoea grades and more restriction in lung function parameters. Nevertheless, the intervention group achieved significant improvement in primary and key secondary outcomes. Further limitations are the small number of patients and the inability to obtain complete dryness of effusion continuously, as defined in the protocol. Dyspnoea associated with pulmonary re-expansion is well known to limit the maximum volume drained. ${ }^{[31-36]}$

\section{Conclusion}

Therapeutic drainage may offer additional medium- and longterm functional benefits to patients with large tuberculous pleural effusions, as is evident by the statistically significant improvement in PFT results compared with anti-TB drugs alone. Pleurodesis is generally a safe procedure, and easy to perform in the primary care setting. We recommend draining the maximum amount of fluid the patient finds comfortable, or continuing until drainage stops spontaneously. This should be followed up by chest radiography to exclude any complications.

Acknowledgement. Funding was obtained from the Susan de Kock bursary for postgraduate study in 2013 . 

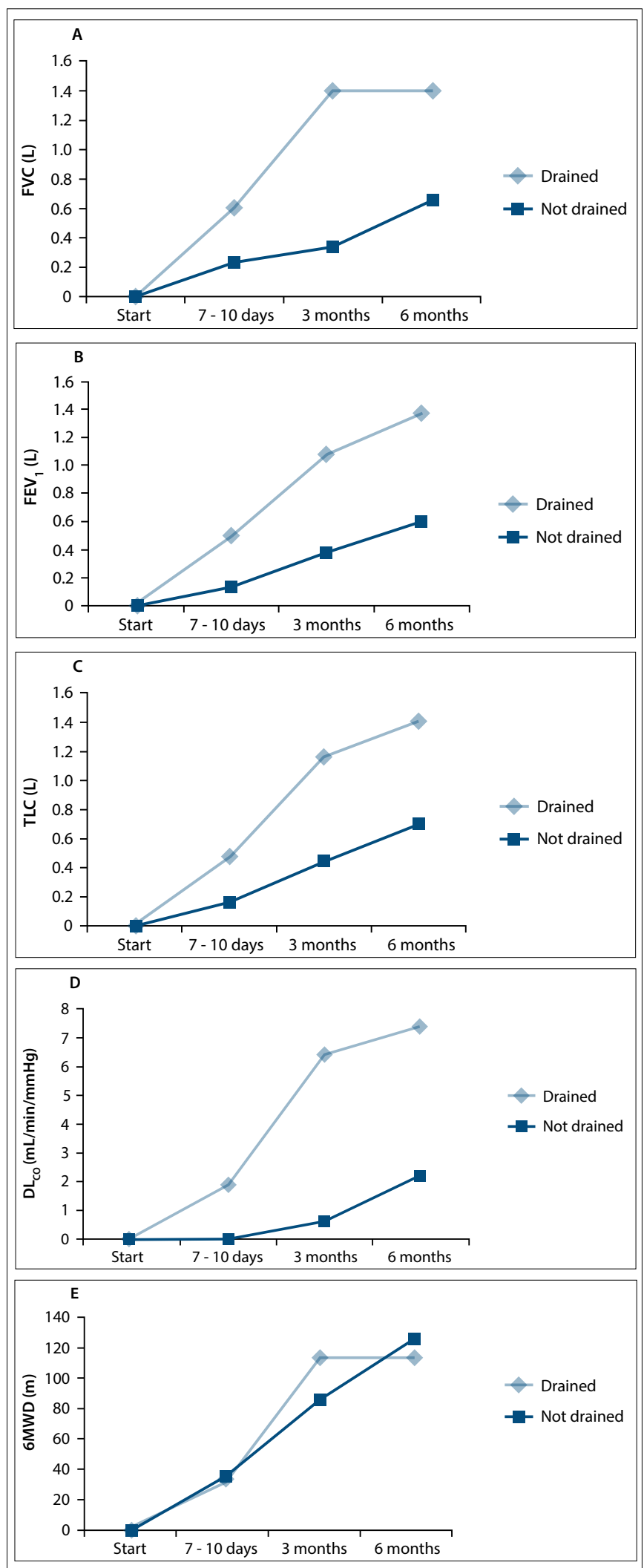

Fig. 2. Mean changes in absolute (A) FVC, (B) FEV , (C) TLC, (D) $D L_{C O}$ and (E) $6 M W D$ from baseline.

\section{References}

1. World Health Organization. Global Tuberculosis Control: Surveillance, Planning, Finances. Geneva: WHO, 2008:19.

2. World Health Organization. Tuberculosis. http://www.who.int/mediacentre/ factsheets/fs104/en/ (accessed 15 March 2016).
3. Jantz MA, Antony VB. Pleural fibrosis. Clin Chest Med 2006;27(2):181-191. DOI:10.1016/j.ccm.2005.12.003

4. Loddenkemper R, Antony VB. Pleural diseases. Eur Respir Monogr 2002;22:270-278. 5. Diacon AH, van de Wal BW, Wyser C, et al. Diagnostic tools in tuberculous pleurisy: A direct comparative study. Eur Respir J 2003;22(4):589-591. DOI:10.1183/09031936.03.00017103a

6. Bolliger CT, de Kock MA. Influence of a fibrothorax on the flow volume curve. Respiration 1988;54(3):197-200. DOI:10.1159/000195522

7. De Pablo A, Villena V, Echave-Sustaeta J, Encuentra AL. Are pleural fluid parameters related to the development of residual pleural thickening in tuberculosis? Chest 1997;112(5):1293-1297. DOI:10.1378/chest.112.5.1293

8. Barbas CS, Cukier A, de Varvalho CR, et al. The relationship between pleural fluid findings and the development of pleural thickening in patients with pleural tuberculosis. Chest 1991;100(5):1264-1267. DOI:10.1378/chest.100.5.1264

9. Lai YF, Chao TY, Wang YH, Lin AS. Pigtail drainage in the treatment of tuberculous pleural effusions: A randomised study. Thorax 2003;58(2):149-152. DOI:10.1136/thorax.58.2.149

10. Chung CL, Chen CH, Yeh CY. Early effective drainage in the treatment of loculated tuberculous pleurisy. Eur Respir J 2008;31(6):1261-1267. DOI:10.1183/09031936.00122207

11. Wong PC. Management of tuberculous pleuritis: Can we do better? Respirology 2005;10(2):144-148. DOI:10.1111/j.1440-1843.2005.00689.x

12. Lai YF, Su MC, Weng HH, et al. Sonographic septation: A predictor of sequelae of tuberculous pleurisy after treatment. Thorax 2009;64(9):806-809. DOI:10.1136/thx.2008.110197

13. Light RW. Update on tuberculous pleural effusion. Respirology 2010;15(3):451-458 DOI:10.1111/j.1440-1843.2010.01723.x

14. World Health Organization. Global Tuberculosis Report 2012. Geneva: WHO, 2012.

15. Miller MR, Crapo R, Hankinson J, et al. General considerations for lung function testing. Eur Respir J 2005;26(1):153-161. DOI:10.1183/09031936.05.00034505

16. Miller MR, Hankinson J, Brusasco V, et al. Standardisation of spirometry. Eur Respir J 2005;26(2):319-338. DOI:10.1183/09031936.05.00034805

17. Wanger J, Clausen JL, Coates A, et al. Standardisation of the measurement of lung volumes. Eur Respir J 2005;26(3):511-522. DOI:10.1183/09031936.05.00035005

18. Pellegrino R, Viegi G, Brusasco V, et al. Interpretative strategies for lung function tests. Eur Respir J 2005;26(5):948-968. DOI:10.1183/09031936.05.00035205

19. American Thoracic Society. ATS statement: Guidelines for the six-minute walk test Am J Respir Crit Care Med 2002;166(1):111-117. DOI:10.1164/ajrccm.166.1.at1102

20. Borg G. Psychophysical bases of perceived exertion. Med Sci Sports Exerc 1982;14(5):377-381. DOI:10.1249/00005768-198205000-00012

21. Koegelenberg CF, von Groote-Bidlingmaier F, Bolliger CT. Transthoracic ultrasonography for the respiratory physician. Respiration 2012;84(4):337-350. DOI:10.1159/000339997

22. Colt H. Closed needle pleural biopsy. In: Light RW, Lee YC, eds. Textbook of Pleura Disease. 2nd ed. London: Hodder \& Stoughton, 2008:557-559.

23. Raja OG, Lalor AJ. Modification to the technique of percutaneous pleural biopsy using Abram's needle. Br J Dis Chest 1980;74(3):285-286. DOI:10.1016/0007-0971(80)90057-1

24. World Health Organization. Treatment of Tuberculosis Guidelines: Guidelines for National Programmes, 4th ed. Geneva: WHO, 2010.

25. Wyser C, Waltzl G, Smedema JP, Swart F, van Schalkwyk EM, van de Wal BW Corticosteroids in the treatment of tuberculous pleurisy: A double blind, placebocontrolled randomized study. Chest 1996;110(2);333-338.

26. Bhuniya S, Arunabha DC, ChoudhuryS, Saha I, RoyTS, Saha M. Roleof therapeuticthoracentesisin tuberculous pleural effusion. Ann Thorac Med 2012;7(4):215-219.DOI:10.4103/1817-1737.102176

27. Brown NE, Zamel N, Aberman A. Changes in pulmonary mechanics and gas exchange following thoracocentesis. Chest 1978;74(5);540-542.

28. Cartaxo AM, Vargas FS, Salge JM. Improvement in the 6-min walk test and spirometry following thoracentesis for symptomatic pleural effusions. Chest 2011;139(6);14241429. DOI:10.1378/chest.10-1679

29. Zerahn B, Jensen BV, Olsen F, Petersen JR, Kanstrup IL. The effect of thoracentesis on lung function and transthoracic electrical bio impedance. Respir Med 1999;93(3);196201. DOI:10.1016/s0954-6111(99)90008-2

30. Wise RA, Brown CD. Minimal clinically important differences in the six-minute walk test and the incremental shuttle walk test. J Chron Obstruct Pulmon Dis 2005;2(1):125-129. DOI:10.1081/copd-200050527

31. Estenne M, Yernault JC, de Troyer A. Mechanism of relief of dyspnoea after thoracocentesis in patients with large pleural effusions. Am J Med 1983;74(5):813-819. DOI:10.1016/00029343(83)91072-0

32. Candela A, Andujar J, Hernaéndez L, et al. Functional sequelae of tuberculous pleurisy in patients correctly treated. Chest 2003;123(6);1996-2000. DOI:10.1378/chest.123.6.1996

33. Feller-Kopman D, Berkowitz D, Boiselle P, Ernst A. Large-volume thoracentesis and the risk of re-expansion pulmonary oedema. Ann Thorac Surg 2007;84(5):1656-1661. DOI:10.1016/j.athoracsur.2007.06.038

34. Villena V, Lopez-Encuentra A, Pozo F, de-Palbo A, Martin-Escribano P. Measurement of pleural pressure during therapeutic thoracentresis. Am J Respir Crit Care Med 2000;162(4):1534-1538. DOI:10.1164/ajrccm.162.4.9907047

35. Light RW, Jenkinson SG, Minh VD, George RB. Observations on pleural fluid pressures as fluid is withdrawn during thoracentesis. Am Rev Respir Dis 1980;121(5):799-804.

36. Feller-Kopman D, Walkey A, Berkowitz D, Ernst A. The relationship of pleural pressure to symptom development during therapeutic throracentesis. Chest 2006;129(6);15561560. DOI:10.1378/chest.129.6.1556 